\title{
Em busca de uma educação política para estudantes de Odontologia: percepções acerca do fenômeno político e suas aproximações
}

Márcia Rosana Farias de Oliveira Alencar Vidal*; Leonardo Carnut**; Luiz Gutenberg Toledo de Miranda Coelho Junior**; Celso Zilbovicius***

\footnotetext{
Graduanda em Odontologia, Campus Arcoverde, Universidade de Pernambuco (UPE)

** Professor de Saúde Coletiva do Curso de Graduação em Odontologia, Campus Arcoverde, Universidade de Pernambuco (UPE)

*** Professor do Departamento de Odontologia Social do Curso de Graduação em Odontologia, Faculdade de Odontologia, Universidade de São Paulo (FOUSP)
}

\section{RESUMO}

Considerando a educação humanística como uma condição necessária para formação política em odontologia, objetivou-se identificar a percepção de estudantes acerca da política nos conteúdos de saúde bucal coletiva e se é possível, assim, realizar uma educação política desses estudantes. Uma intervenção pedagógica do tipo investigaçãoação foi realizada cujo cenário foi a disciplina 'Saúde coletiva II' no Curso de Odontologia do Campus Arcoverde da Universidade de Pernambuco. Dezessete estudantes do $2^{\circ}$ período participaram elaborando resenhas sobre suas percepções sobre política a partir do conteúdo estudado. Usou-se o método de Análise de Conteúdo de Bardin a partir das resenhas para definir se, o que foi identificado como 'política', se aproximava de um letramento político. Totalizou-se 185 ideias sobre política que foram agrupadas em oito categorias: 'Trânsito da Odontologia entre a perspectiva integral e a perspectiva técnica', 'Informação como requisito essencial', 'As políticas públicas de saúde (operacionalização via Estado)', 'Participação dos envolvidos nas decisões', 'Planejamento das ações de saúde', 'A formação do cirurgião-dentista', 'O saber da Saúde Bucal Coletiva' e 'Portarias ministeriais'. $70,3 \%$ dessas ideias parecem servir para um letramento político. Conclui-se que parece haver um caminho pedagógico que pode ser percorrido para se obter um letramento político dos estudantes de odontologia investigados.

Descritores: Educação em Odontologia. Política. SUS. Saúde Bucal. Ensino. 


\section{INTRODUÇÃO}

Generalista, humanista e reflexivo. Essas são as características essenciais que se deve perseguir para a formação de cirurgiõesdentistas contemporâneos segundo as Diretrizes Curriculares Nacionais (DCN $)^{1}$. No entanto, alcançar estes objetivos tem sido um esforço hercúleo por parte de docentes e estudantes para superar a inspiração flexneriana ${ }^{2}$ que, de uma maneira geral, está imbricada no ensino dos cursos biomédicos.

O principal desafio da área se trata do 'espaço odontológico' (e, sem esquecer do seu fetiche - a cárie $)^{3}$ que dificulta a generalidade, o humanismo e a reflexão do processo ensinoaprendizagem. Com base nas sucessivas emergências paradigmáticas ${ }^{4}$ que vem provendo "a luz" ao "aluno", uma visão global do ser humano tem sido resgatada ressaltando o ser social e destacando a imprescindível experiência dos indivíduos ${ }^{4}$ na construção do seu saber ${ }^{6}$.

Neste cenário, os alunos detêm o protagonismo da sua cognição, do seu desenvolvimento ${ }^{7} \mathrm{e}$, por consequência, do seu 'fazer' que decorre desse processo educativo ${ }^{8}$. Assim, esperar dos formandos em odontologia apenas repetições de preparos cavitários, inserções de materiais restauradores ou exodontias clinicamente seguras não passa de um adestramento cirúrgico, que, apesar de essencial, se reproduz acriticamente.

Mesmo com os avanços trazidos pelas mudanças curriculares ${ }^{9}$, o conceito positivo de saúde $^{10}$ e uma cultura assistencial humanizada $^{11}$, a conjuntura socio-histórica pós-anos '90 de constante solapamento dos direitos sociais ${ }^{12}$, impôs uma nova agenda: defender o direito à saúde e o amparo desta como um bem coletivo. Para isso é necessária uma leitura embasada do cenário social vigente $^{13} \mathrm{e}$ mais precisamente, da apropriação da categoria 'política' em suas mais diversas acepções.

Em Odontologia, a preocupação com tema 'política' nunca ganhou notoriedade. Como bem registrado por Amorim et al $(2007)^{14}$, dentre as três principais revistas odontológicas nacionais, no período 19932004, os artigos relacionados à políticaleconomia ou temas assemelhados compuseram $0,78 \%$ do total dos artigos (2.086). Quando se desagregou a frequência da categoria pelas revistas, em duas delas, os artigos sobre política, dentre 25 colocações, ocupavam a última posição.

Educar politicamente não é uma tarefa trivial $^{15}$. No entanto, Lipset $(1967)^{16}$ já evidenciava o poder da educação no desenvolvimento político da pessoa quando coloca que:

“...mesmo não sendo possível afirmar que um "alto nível" de educação é uma condição suficiente para a democracia, os estudos sugerem que esta é, no mínimo, uma condição necessária" (LIPSET, 1967).

Nesta esteira, tomando-se a educação como uma 'condição necessária' nas palavras de Lipset $(1967)^{16}$, Aciole (2007) ${ }^{17}$ reforça que quaisquer formas de tomada de consciência sanitária (enquanto cidadão portador de direitos e deveres perante o Estado) requer, sim, um investimento pedagogicamente orientado.

Assim, uma saída para esse impasse, pode ser a garantia de uma pedagogia que favoreça a discussão política em sentido lato a semelhança do que Cosson $(2010)^{18}$ descreve como um 'letramento político'. Este autor 
define o letramento político como o processo de apropriação de 'práticas', 'conhecimentos' e 'valores' para a manutenção e aprimoramento da 'democracia' e tem a função de ser permanente e articulado com todos os componentes e vivências práticas exercidas em um processo de formação. É, ainda, chamado de 'político' pois foca na construção da compreensão e da participação consciente na vida política.

Para fomentar essa construção, o curso de Odontologia do Campus Arcoverde da Universidade de Pernambuco (UPE) tem uma matriz curricular baseada no que está preconizado pelas Diretrizes Curriculares Nacionais (DCN) na qual dois eixos humanísticos percorrem o curso longitudinalmente.

Um deles é o Eixo "Saúde Humana" que versa sobre as competências relativas à visão coletiva da saúde em uma perspectiva humanista holística (biopsicossocial) percorrendo do $1^{\circ}$. ao $6^{\circ}$. período, e outro, o Eixo "Compromisso Social" que versa sobre as competências relativas à construção da visão crítica e reflexiva sobre o ser humano e à sociedade (10. ao 8o. período), visando construir uma postura de cidadãos conscientes e críticos da realidade social brasileira, que defendam o direito à saúde e que possam fazer escolhas políticas racionais.

Em busca de verificar a factibilidade desse projeto, este estudo visa fazer uma identificação inicial sobre quais são conteúdos de saúde bucal coletiva que conduziriam os estudantes a um letramento político. Assim, dois objetivos específicos precisaram ser alcançados: a) o que os estudantes percebem sobre a 'política' nos textos estudados, e b) se, dentre os conteúdos que foram percebidos como 'política' nos textos estudados são suficientes para proporcionar o letramento político nesses estudantes.

\section{PERCURSO METODOLÓGICO}

Tratou-se de uma pesquisa de intervenção pedagógica classificada como uma investigação-ação. Bogdin e Biklen $(1994)^{19}$ afirmam que esta proposta nos instiga a ganhar confiança sobre uma situação, já que é difícil empenharmo-nos entusiasticamente em um determinado objeto quando só nos baseamos em sentimentos, sem dados para sustentar nossas posições. Assim, a investigação-ação nos auxilia a compreender melhor os fatos com o objetivo de tomar uma posição mais credível para audiências mais vastas.

O cenário pedagógico deste estudo foi o componente curricular "Saúde coletiva II". Esse componente foi o escolhido por ter como ementa os conteúdos relativos à Saúde Bucal Coletiva (SBC), o que de certa forma, gera identificação do estudante com o assunto devido ao apelo à região da boca e dos dentes fortemente associado à representação social da profissãa ${ }^{3}$.

Quanto à produção dos dados, usaramse resenhas escritas pelos sujeitos de pesquisa ${ }^{19}$ sobre os temas relativos ao que se considera a 'literatura fundamental da saúde bucal coletiva' que se trata de artigos e/ou documentos públicos dos seguintes assuntos: introdução à epidemiologia bucal; introdução à política, planejamento e gestão em saúde bucal; introdução às ciências sociais em saúde bucal; saúde bucal no SUS I (normatização estruturante de 2000 a 2004); saúde bucal no SUS II (de 2006 em diante); histórico das políticas públicas de saúde no Brasil e atenção 
à saúde bucal na Estratégia de Saúde da Família.

Os estudantes foram orientados a escrever uma resenha, de até quatro parágrafos sobre $\mathrm{o}$ tema em estudo identificando o quê, em cada tema, é perceptível como um elemento ou expressão do fenômeno político em sua opinião. Assim, todos os 17 estudantes do $2^{\circ}$. Período do curso de graduação em Odontologia do Campus Arcoverde da UPE foram sujeitos de pesquisa, portanto nenhum estudante foi excluído do trabalho.

Após a confecção, o conteúdo das resenhas expressava as percepções dos estudantes acerca do que eles puderam identificar como um aspecto político relacionado ao assunto estudado. Usou-se o método de análise de conteúdo recomendado por Bardin (2009) ${ }^{20}$ para definir se o que foi identificado como 'política' se aproximava do que Cosson $(2010)^{18}$ admite como conhecimentos para um letramento político. A identificação das ideias centrais recaiu sobre o parágrafo ('corpus') nos quais os estudantes relacionavam o assunto com o que eles percebiam por 'política'.

A construção das categorias seguiu a lógica de emergência apresentada nos textos, sendo agrupadas segundo critérios de semelhança léxico-semântica. Assim, baseouse no roteiro metodológico da Análise de Respostas a Questões Abertas proposta por Bardin $^{20}$, cujo foco nessa pesquisa foi identificar a política (em seu sentido lato) e sua aproximação com os conhecimentos para o letramento político. Tratou-se, portanto, de uma análise inicial reservada a uma breve descrição de frequência destes conteúdos.
Por fim, obteve-se um panorama da percepção dos estudantes sobre o fenômeno político advindo dos textos estudados no qual se traçou uma análise descritiva inicial das ideias centrais e seu agrupamento em categorias. Após esse primeiro esforço, foram sistematizados os elementos semântico(sintáticos) que, de acordo com o conceito de 'letramento político', podem servir de base para uma educação política dos estudantes de odontologia.

\section{RESULTADOS}

Dentre os 17 alunos que frequentaram o componente curricular 'Saúde Coletiva II', cada um realizou 15 resenhas, o que deveria totalizar 255 resenhas, contudo 70 resenhas não foram incluídas por estarem fora dos padrões instituídos pela metodologia de ensino do componente. Assim, totalizou-se 185 resenhas como material escrito produzido pelos sujeitos.

Dentre as 185 ideias centrais (1 por resenha) identificadas como 'políticas' foi pertinente descrever o significado das categorias e ideias centrais as quais os parágrafos apresentaram. Essas ideias centrais foram agrupadas em oito categorias que as reúnem por semelhança léxico-semântica (figura 1). Foram estas: 'Trânsito da Odontologia entre a perspectiva integral e a perspectiva técnica', 'Informação como requisito essencial', 'As políticas públicas de saúde (operacionalização via Estado)', 'Participação dos envolvidos nas decisões', 'Planejamento das ações de saúde', 'A formação do cirurgião-dentista', 'O saber da Saúde Bucal Coletiva' e 'Portarias ministeriais'. 


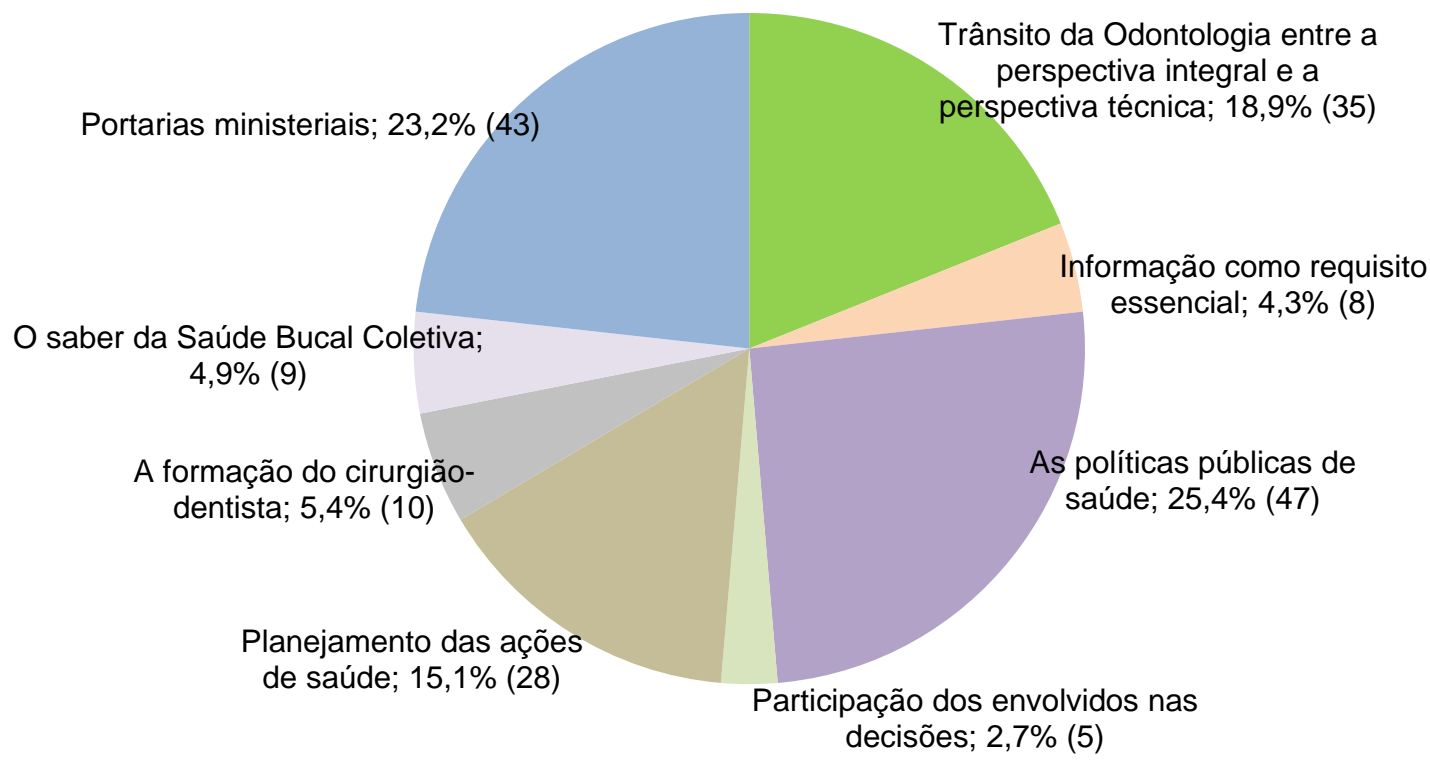

Figura 1. Proporção das categorias identificadas a partir do agrupamento das ideias centrais apresentadas pelos estudantes de odontologia sobre política nos conteúdos de SBC estudados

Sete ideias centrais puderam ser agrupadas na categoria 'Trânsito da Odontologia entre a perspectiva integral e a perspectiva técnica', as quais são: (a) 'Prática odontológica'; (b) 'Tratamento curativomutilador';

'Odontologia/ homem/sociedade'; (d) 'Cárie'; (e) 'Aspectos sociais' e (f) 'Estudos sobre cárie’: (g) 'Desodontologizar'.

Três ideias centrais puderam ser agrupadas na categoria 'Informação como requisito essencial', as quais são: (a) 'Estar bem informado'; (b) ‘CD não informado e (c) 'Deveres políticos/ESF/Comunidade'.

Sete ideias centrais puderam ser agrupadas na categoria 'As políticas públicas de saúde (operacionalização via Estado)', as quais são: (a) 'Fluoretação': (b) 'Epidemiologia'; (c) 'Investimentos'; (d) 'Intervenção do Estado'; (e) 'Brasil
Sorridente': (f) 'Falta de políticas de promoção à saúde' e (g) 'Saúde bucal no PSF'.

Duas ideias centrais puderam ser agrupadas na categoria 'Participação dos envolvidos nas decisões', as quais são: (a) 'Controle social' e (b) 'Construção da cidadania'.

Quatro ideias centrais puderam ser agrupadas na categoria 'Planejamento das ações de saúde', as quais são: (a) 'Programação das ações'; (b) 'Falha no planejamento'; (c) 'Reorientação do trabalho' e (d) 'Planejamento/prática'.

Duas ideias centrais puderam ser agrupadas na categoria 'A formação do cirurgião-dentista', as quais são: (a) 'Formação profissional humanística' e (b) 'Mudanças no modelo assistencial'.

Quatro ideias centrais puderam ser 
agrupadas na categoria 'O saber da Saúde Bucal Coletiva', as quais são: (a) 'Agenda para saúde bucal coletiva'; (b) 'Conferências/conquistas'; (c) 'Reivindicações' e (d) 'Desafios'.

$\mathrm{Na}$ categoria 'Portarias ministeriais': os estudantes parafrasearam os principais incisos e artigos das portarias estudadas, assim como eles conseguiam entender que suas matérias são diferentes entre si. Todas as ideias centrais supracitadas podem ser vistas sumariamente na figura 1 .

Dentre as categorias descritas acima, as ideias centrais relacionadas às 'Políticas públicas de saúde (operacionalização via Estado)' foram as mais frequentes $(25,4 \%)$, seguidas das 'Portarias ministeriais' que representam $23,2 \%$ do total de ideias centrais que os estudantes identificaram como ideias 'políticas'.

Após análise do conteúdo dessas ideias de acordo com o que se preconiza para um letramento político, em geral, a maioria $(70,3 \%)$ das ideias centrais apresentadas pelos estudantes de odontologia do $2^{\circ}$ período em suas resenhas se aproximavam com noções sobre política que subsidiam um letramento político.

Em contrapartida, $29,7 \%$ das ideias centrais apresentadas pelos estudantes em suas resenhas, apesar destes considerarem estes conteúdos como 'políticos' após a análise empreendida pelos pesquisadores, pôde-se perceber que não se aproximam de qualquer conhecimento para a compreensão da democracia que subsidiaria um letramento político.

Dentre as categorias que apresentaram maior frequência de ideias centrais que não se aproximam de um letramento político são o
'Trânsito da Odontologia entre a perspectiva integral e a perspectiva técnica' $(57,1 \%)$ e o 'Planejamento das ações em saúde' (50\%) (tabela 1).

\section{DISCUSSÃO}

Nessa pesquisa, os estudantes foram alvo de uma intervenção pedagógica ${ }^{21}$ pois, no decorrer do processo de ensinoaprendizagem, adquiriram conhecimentos relativos à saúde bucal coletiva que lhes fizeram repensar o modo como a Odontologia se insere no tempo social vigente e quais a características políticas que ela deve deter nessa visão ideológica de mundo.

Assim, é importante lembrar a evolução processual que os estudantes obtiveram no contato com o conteúdo. Para chegar a tal resultado entendemos que a literatura sobre Saúde Bucal Coletiva (SBC) foi essencial para que desenvolvessem suas capacidades crítico-reflexivas sobre o panorama atual da saúde coletiva e a odontologia. Somente sob esta intervenção, os estudantes conseguiram fazer uma conexão mais viável entre o que foi estudado e uma ideia genérica sobre 'política' presente em seus estoques de conhecimento ${ }^{22}$.

No caso dessa pesquisa, a categoria que os estudantes mais referenciaram como 'política' foram aquelas em que o significado está associado ao aparelho do Estado e sua intervenção via políticas públicas assim como as normas (portarias) fruto da positivação jurídica dessas políticas.

A categoria que os estudantes menos identificaram como 'política' foi àquela relacionada à 'participação dos envolvidos nas decisões'. Isso pode ser reflexo da organização sociopolítica em que a Odontolo- 
Tabela 1. Proporção das ideias centrais relacionadas à política por categoria identificadas pelos estudantes segundo aproximação dos parágrafos com o conceito de letramento político (continua).

\begin{tabular}{|c|c|c|c|c|c|c|c|}
\hline \multirow[t]{2}{*}{ Categorias } & \multirow[t]{2}{*}{ Ideias Centrais } & \multicolumn{2}{|c|}{$\begin{array}{l}\text { O conteúdo do parágrafo } \\
\text { se aproxima do conceito } \\
\text { de letramento político }\end{array}$} & \multicolumn{2}{|c|}{$\begin{array}{l}\text { O conteúdo do parágrafo } \\
\text { não se aproxima do } \\
\text { conceito letramento } \\
\text { político }\end{array}$} & \multicolumn{2}{|c|}{ TOTAL } \\
\hline & & $\mathrm{N}$ & $\%$ & $\mathrm{~N}$ & $\%$ & $\mathrm{~N}$ & $\%$ \\
\hline \multirow{8}{*}{$\begin{array}{l}\text { Trânsito da Odontologia entre a } \\
\text { perspectiva integral e a } \\
\text { perspectiva técnica }\end{array}$} & Prática odontológica & 4 & 66,6 & 2 & 33,3 & 6 & 100,0 \\
\hline & Tratamento curativo-mutilador & 1 & 25,0 & 3 & 75,0 & 4 & 100,0 \\
\hline & Odontologia-homem-sociedade & 3 & 100,0 & 0 & - & 3 & 100,0 \\
\hline & Cárie & 1 & 1,1 & 8 & 8,8 & 9 & 100,0 \\
\hline & Aspectos sociais & 1 & 50,0 & 1 & 50,0 & 2 & 100,0 \\
\hline & Estudo sobre cárie & 2 & 33,3 & 4 & 66,6 & 6 & 100,0 \\
\hline & Desodontologizar a saúde bucal & 3 & 60,0 & 2 & 40,0 & 5 & 100,0 \\
\hline & Total & 15 & 42,8 & 20 & 57,1 & 35 & 100,0 \\
\hline \multirow{4}{*}{$\begin{array}{l}\text { Informação como requisito } \\
\text { essencial }\end{array}$} & Estar bem informado & 1 & 100,0 & 0 & - & 1 & 100,0 \\
\hline & CD não informado & 4 & 80 & 1 & 20 & 5 & 100,0 \\
\hline & Deveres políticos/ESF/comunidade & 1 & 50 & 1 & 50 & 2 & 100,0 \\
\hline & Total & 6 & 75,0 & 2 & 25,0 & 8 & 100,0 \\
\hline \multirow{8}{*}{$\begin{array}{l}\text { As políticas públicas de saúde } \\
\text { (operacionalização via Estado) }\end{array}$} & Fluoretação & 5 & 100,0 & 0 & - & 5 & 100,0 \\
\hline & Epidemiologia & 10 & 50,0 & 10 & 50,0 & 20 & 100,0 \\
\hline & Investimentos & 1 & 100,0 & 0 & - & 1 & 100,0 \\
\hline & Intervenção do estado & 8 & 72,7 & 3 & 27,3 & 11 & 100,0 \\
\hline & Brasil sorridente & 2 & 66,6 & 1 & 33,3 & 3 & 100,0 \\
\hline & Falta de políticas de promoção à saúde & 1 & 100 & 0 & - & 1 & 100,0 \\
\hline & Saúde bucal no PSF & 3 & 50 & 3 & 50 & 6 & 100,0 \\
\hline & Total & 30 & 63,8 & 17 & 36,2 & 47 & 100,0 \\
\hline
\end{tabular}




\begin{tabular}{|c|c|c|c|c|c|c|c|}
\hline & & & & & & \multicolumn{2}{|c|}{ (continuação) } \\
\hline \multirow{3}{*}{$\begin{array}{l}\text { Participação dos envolvidos nas } \\
\text { decisões }\end{array}$} & Controle social & 2 & 100,0 & 0 & - & 2 & 100,0 \\
\hline & Construção da cidadania & 3 & 100,0 & 0 & - & 3 & 100,0 \\
\hline & Total & 5 & 100,0 & $\mathbf{0}$ & $\mathbf{0}$ & 5 & 100,0 \\
\hline \multirow{4}{*}{$\begin{array}{l}\text { Planejamento das ações de } \\
\text { saúde }\end{array}$} & Programação das ações & 4 & 44,4 & 5 & 55,5 & 9 & 100,0 \\
\hline & Falha no planejamento & 3 & 42,8 & 4 & 57,1 & 7 & 100,0 \\
\hline & Reorientação de trabalho & 4 & 44,4 & 5 & 55,5 & 9 & 100,0 \\
\hline & Prática do planejamento & 3 & 100,0 & 0 & - & 3 & 100,0 \\
\hline \multirow{3}{*}{$\begin{array}{l}\text { A formação do cirurgião- } \\
\text { dentista }\end{array}$} & Formação profissional humanística & 3 & 100,0 & 0 & - & 3 & 100,0 \\
\hline & Mudanças no modelo assistencial & 6 & 85,7 & 1 & 14,2 & 7 & 100,0 \\
\hline & Total & 9 & 90 & 1 & 10 & 10 & $\mathbf{1 0 0 , 0}$ \\
\hline O saber da Saúde Bucal & Agenda para saúde bucal coletiva & 1 & 50,0 & 1 & 50,0 & 2 & 100,0 \\
\hline \multirow[t]{3}{*}{ Coletiva } & Conferência/conquistas & 1 & 100,0 & 0 & - & 1 & 100,0 \\
\hline & Reivindicações & 2 & 100,0 & 0 & - & 2 & 100,0 \\
\hline & Desafios & 4 & 100,0 & 0 & - & 4 & 100,0 \\
\hline \multirow[t]{3}{*}{ Portarias ministeriais } & $\begin{array}{l}\text { Os estudantes fazem relação direta com } \\
\text { a política. }\end{array}$ & 43 & 100,0 & 0 & - & 43 & 100,0 \\
\hline & Total & 43 & 100,0 & $\mathbf{0}$ & - & 43 & 100,0 \\
\hline & Total Geral & 130 & 70,3 & 55 & 29,7 & 185 & 100,0 \\
\hline
\end{tabular}


gia se encontra no contexto atual no qual a participação em fóruns de decisão sobre a profissão não contempla o envolvimento estudantil como atores políticos legítimos.

Outros fóruns de decisão, assim como os conselhos e conferências no SUS ainda carecem da participação do cirurgião-dentista e por isso também podem ser compreendidos pelos estudantes como espaços de decisão em que sua participação não seja essencial. Essas hipóteses sugerem que os estudantes não conseguem perceber a participação como um processo político por natureza.

Dentre as categorias que não se aproximam de uma ideia sobre política que subsidiariam um letramento são o 'Trânsito da Odontologia entre a perspectiva integral e a perspectiva técnica' e o 'Planejamento das ações em saúde'. Do ponto de vista das ideias centrais destas categorias que servem como subsídios para um possível letramento político os seguintes achados chamaram a atenção por suas contradições.

Na categoria 'Trânsito da Odontologia entre a perspectiva integral e a perspectiva técnica', a primeira contradição reside na ideia do tratamento curativo-mutilador. Os estudantes apontam que a odontologia é responsável pelas mutilações, mas não compreenderem que o cirurgião-dentista é o ator político que detém o poder da organização do conhecimento e, em certa medida, o monopólio da escolha terapêutica. Se o número de extrações dentárias foi exagerado no passado, isto refletia a prática de organização política do conhecimento na qual os produtores do saber dessa disciplina admitem como essenciais para protegerem seus interesses enquanto campo científico ${ }^{23} \mathrm{e}$ grupo econômico ${ }^{24}$.
A segunda se baseia no fato dos estudantes enxergarem a necessidade de entender o homem como ser biopsicossocial, indivisível, não só como um dente cariado, mas não expressam o valor associado à compreensão limitada que o 'espaço odontológico' conforma a visão de homem (e de mundo) de suas interpretações assim como a redução do seu campo de trabalho como uma escolha política datada do século $\mathrm{XIX}^{3}$. É compreensível perceber que essa contradição se apoia na pouca capacidade que os estudantes têm em refletirem sobre como são moldados a reforçar a ausência do valor político dessa extrapolação devido à força coercitiva proporcionada pela representação social da profissão.

A terceira contradição nessa categoria se relaciona aos 'Estudos sobre cárie'. Nesta, os estudantes tecem comentários sobre a evidência de ausência de declínio da cárie em função da grande quantidade de cirurgiõesdentistas. Contudo, não expressam que a organização política da categoria, apoiada na ideia do tecnicismo e biologicismo flexnerianos sustentou a tese de uma prática assistencial orientada para o mercado. Através dessa perspectiva liberal da prática profissional, se escamoteia o valor político da escolha dessa categoria que não consegue ser percebida pelos estudantes nesse estudo.

Outras contradições foram evidentes na categoria 'Planejamento das ações em saúde'. Nas ideias centrais relacionadas à 'Programação das ações'; 'Falhas no planejamento' e 'Reorientação do trabalho' foi possível identificar que, na metade dos casos, o que foi descrito pelos estudantes não é suficiente para um letramento político, onde o planejamento só serviria para discussão dos 
conhecimentos democraticamente quando se localiza em âmbito central. Isso reforça a hipótese de que os estudantes reconhecem o legislativo (como prática política) mas não reconhecem a prática de planejar em nível local como política em si mesma.

Saindo da análise das categorias e partindo para uma análise das ideias centrais isoladamente, algumas destas chamaram atenção por não se configurarem como conteúdos para um letramento político.

A ideia central sobre 'epidemiologia' foi uma delas. Metade (50\%) dos parágrafos ressaltam as características políticas para o letramento e a outra metade não. Parece que metade dos estudantes não compreendem a epidemiologia como uma prática de produção de informações que subsidiam a tomada de decisões em saúde. Isso remete ao esvaziamento do conteúdo político das informações epidemiológicas ${ }^{25}$. As informações epidemiológicas, conforme explicita Narvai (2006) ${ }^{26}$, são fonte de poder pois devem orientar as ações práticas no âmbito dos serviços.

Na ideia sobre 'saúde bucal no PSF' se identifica uma clara divisão entre aqueles parágrafos que apresentam um conteúdo que subsidia um letramento político ou outros não. Destaca-se a instrumentalização gerencial do PSF enquanto prática assistencial desvinculada de uma prática social e comunitária, portanto sem valor político em sua essência. Essa percepção pode ocorrer pelo fato dos estudantes não perceberem que a prática sanitária do cirurgião-dentista na Estratégia de Saúde da Família transcende a questão ambulatorial per se e requer um avanço para além das práticas biomédicas assentando-se, sobretudo, na prática comunitária e articulação política para saúde em seu território adstrito de trabalho.

Talvez, todo o cerne da discussão sobre as categorias anteriormente analisadas esteja localizado no quê os estudantes entendem por 'informação'. Ao analisarmos a ideia a respeito dos 'deveres políticos/ESF/comunidade' foi possível identificar que esta ideia é a única que, dentro de todo $o$ sentido fundamental sobre informação, não se aproxima do que pode servir para um letramento político. Mesmo a maior parte dos parágrafos identificando que a informação é um insumo essencial e o problema do CD 'mal informado' são constatações que justificam o letramento político, o caráter de reorganização da atenção básica com o programa de saúde da família deixa a desejar no sentido da equidade, pois não atinge toda população. Para maior parte dos parágrafos analisados com essa ideia central não foi possível identificar como práticas, valores ou conhecimentos dessa ideia são fundamentos para construção de uma sociedade democrática.

\section{CONSIDERAÇÕES FINAIS}

Segundo os achados dessa pesquisa, os estudantes que são submetidos aos conhecimentos sociais com uma matriz curricular que subsidie a discussão humanística mais aprofundada tendem a compreender política ainda de uma forma instrumentalizada, contudo, com uma tendência de ampliação do objeto do 'fazer político' que transcende a estrutura (Estado) para a agência (vida cotidiana).

Nesse sentido, parece haver um caminho pedagógico que pode ser percorrido para se obter um letramento político dos 
estudantes de odontologia investigados. Esse caminho requer o que o corpo docente invista seu tempo didático-pedagógico nos conteúdos sobre a participação dos envolvidos nas decisões relacionadas à saúde e o acesso à informação como formas de democratização (sanitária) e ressalte os aspectos políticos relacionados aos conteúdos que valorizam a interação interpessoal como o lócus de onde o ato político emerge (micropolítica do cotidiano das relações).

\section{ABSTRACT \\ In search of a political education for Dentistry students: perceptions on the political phenomenon and its approaches}

Considering humanistic education as a necessary condition for political formation in dentistry, this study aimed to identify students perceptions about politics in contents of the discipline of community oral health and if it is possible, through these contents, to build a political education of these students. For this, a research-action type educational intervention was conducted where the pedagogical scenario was the curricular discipline 'Public health II' of the Dental Course of Universidade de Pernambuco (UPE), Campus Arcoverde. Seventeen students of the $2^{\text {nd }}$ Semester participated in the research making reviews about their perceptions about politics from the content studied in the discipline. A content analysis method according Bardin was used to set up whether the content identified as 'politics' approached a political literacy. A total of 185 views about politics which were grouped into eight categories: 'Movement of Dentistry between full perspective and technical perspective', 'Information as an essential requirement', 'Public health policies (implementation via State)', 'Stakeholder involvement in decision-making',' Planning of health practices', 'The formation of the dentist', 'Knowledge of Public Oral health' and 'Ministerial Decrees'. $70.3 \%$ of these ideas seem to serve as a political literacy. In conclusion, there seems to be an educational path that can be followed to obtain a political literacy of dental students investigated.

Descriptors: Education in Dentistry. Politics. Unified Health System. Oral Health. Teaching.

\section{REFERÊNCIAS}

1. Conselho Nacional de Educação, Câmara de Educação Superior. Resolução CNE/CES 3, de 19 de fevereiro de 2002. Institui Diretrizes Curriculares Nacionais do Curso de Graduação em Odontologia. Brasília: Ministério da Educação, 2002.

2. Almeida-Filho N. Reconhecer Flexner: inquérito sobre produção de mitos na educação médica no Brasil contemporâneo. Cad Saude Publica. 2010; 26(12): 2234-49.

3. Botazzo C. A cárie dentária como fetiche - primeiras notas. In: Botazzo C, Oliveira MA. (orgs). Atenção básica no Sistema Único de Saúde: abordagem interdisciplinar para os serviços de saúde bucal. São Paulo: Páginas \& Letras Editora e Gráfica, 2008, p. 219-238.

4. Behrens MA. Paradigmas inovadores $-\mathrm{a}$ produção do conhecimento. In: . O paradigma emergente e a prática pedagógica. Petrópolis, RJ: Vozes 2009, p. 53-91.

5. Mondin B. O problema pedagógico. In: Introdução à filosofia: problemas, sistemas, autores, obras. São Paulo: Paulus, 1980, p. 122-132.

6. Vygotsky LS. Pensamiento y Lenguaje. La Habana: Editora Revolucionaria, 1982. 
7. Brym RJ et al. Sociologia - Sua bússola para um novo mundo. São Paulo: Cengage Learning, 2008. 585 p.

8. Freire P. Pedagogia da autonomia: saberes necessários à prática educativa. 47 . ed. Rio de Janeiro: Paz \& Terra. 2013. $144 \mathrm{p}$.

9. Noro LRA. Construir conhecimentos, integrar vidas. Rev ABENO. 2007; 7(2): 135-140.

10. World Health Organization. The Ottawa charter for health promotion. Geneve: WHO; 1986.

11. Mota LQ, Farias DBLM, Santos TA. Humanização no atendimento odontológico: acolhimento da subjetividade dos pacientes atendidos por alunos de graduação em Odontologia. Rev Bras Ciencias da Saude. 2012; 16(4):537-44.

12. Martiniano C. A luta pela vinculação de recursos para Saúde Pública no Brasil a partir do paradigma da universalização. In: Davi J, Martiniano C, Patriota LM (orgs.). Seguridade social e saúde: tendências e desafios. $2^{\mathrm{a}}$. Edição. Campina Grande-PB: EDUEPB, 2011, p. 85-116.

13. Carvalho SR. Os múltiplos sentidos da categoria "empowerment" no projeto de Promoção à Saúde. Cad Saude Publica. 2004; 20(4): 1088-95.

14. Amorim KPC et al. A construção do saber em Odontologia: a produção científica de três periódicos brasileiros de 1990 a 2004. Interface (Botucatu). 2007; 11,(21): 9-23.

15. Benevides MVM. Educação para democracia. Lua Nova. 1996; 38: 223-37.

16. Lipset SM. O Homem político. Rio de
Janeiro: Zahar Editores. 1967.

17. Aciole GG. Das dimensões pedagógicas para a construção da cidadania no exercício do controle social. Interface (Botucatu). 2007; 11(23): 409-26.

18. Cosson R. Letramento político: por uma pedagogia da democracia. Cadernos Adenauer: Educação política: reflexões e práticas democráticas. 2010; 3:25-36.

19. Bogdin R, Biklen S. O texto escrito pelos sujeitos. In: Investigação qualitativa em educação: uma introdução à teoria e aos métodos. Porto, Portugal: Porto Editora. 1994, p. 176-182.

20. Bardin L. Análise de conteúdo. Lisboa: Edições 70, 2009. 281 p.

21. Pimenta SG, Anastasiou LGC. O docente do ensino superior. In: Docência no ensino superior. $5^{\mathrm{a}}$. ed. São Paulo: Cortez. 2011, p. 177-199.

22. Turner JH. Capítulo 4. Estrutura social. In: _ _ Sociologia - Conceitos e Aplicações. São Paulo: Makron Books, 2000. pp. 47-60.

23. Bourdieu P. Razões Práticas: sobre a teoria da ação. Campinas: Papirus, 1996. $231 \mathrm{p}$.

24. Vieira C, Costa NR. Estratégia profissional e mimetismo empresarial: os planos de saúde odontológicos no Brasil. Cien Saude Colet. 2008; 13(5): 1579-88.

25. Barata RB. Capítulo 1. O que queremos dizer com desigualdades sociais em saúde. In: Como e por que as desigualdades sociais fazem mal à saúde? Rio de Janeiro: Editora Fiocruz, 2009.

26. Narvai PC, Frazão P. Epidemiologia, política e saúde bucal coletiva. In: Antunes JLF, Peres MA. Fundamentos de odontologia - Epidemiologia da saúde 
bucal. Rio de Janeiro: Guanabara Correspondência para:

Koogan, 2006, p. 346-362.

Leonardo Carnut

e-mail: leonardo.carnut@upe.br

Curso de Odontologia. Campus Arcoverde.

Universidade de Pernambuco (UPE).

Rua Gumercindo Cavalcanti, 420

56512-000 - São Cristóvão - Arcoverde, PE. 